\title{
Complementing thermosteric sea level rise estimates
}

\author{
K. Lorbacher ${ }^{1}$, A. Nauels ${ }^{1}$, and M. Meinshausen ${ }^{1,2}$ \\ ${ }^{1}$ Australian-German College of Climate \& Energy Transitions, School of Earth Sciences, The University of Melbourne, \\ Parkville 3010, Victoria, Australia \\ ${ }^{2}$ The Potsdam Institute for Climate Impact Research, Telegrafenberg A26, 14412 Potsdam, Germany
}

Correspondence to: K. Lorbacher (katja.dommenget@unimelb.edu.au)

Received: 9 December 2014 - Published in Geosci. Model Dev. Discuss.: 10 February 2015

Revised: 1 June 2015 - Accepted: 11 August 2015 - Published: 2 September 2015

\begin{abstract}
Thermal expansion of seawater has been one of the most important contributors to global sea level rise (SLR) over the past 100 years. Yet, observational estimates of this volumetric response of the world's oceans to temperature changes are sparse and mostly limited to the ocean's upper $700 \mathrm{~m}$. Furthermore, only a part of the available climate model data is sufficiently diagnosed to complete our quantitative understanding of thermosteric SLR (thSLR). Here, we extend the available set of thSLR diagnostics from the Coupled Model Intercomparison Project Phase 5 (CMIP5), analyze those model results in order to complement upperocean observations and enable the development of surrogate techniques to project thSLR using vertical temperature profile and ocean heat uptake time series. Specifically, based on CMIP5 temperature and salinity data, we provide a compilation of thermal expansion time series that comprise $30 \%$ more simulations than currently published within CMIP5. We find that 21st century thSLR estimates derived solely based on observational estimates from the upper $700 \mathrm{~m}$ $(2000 \mathrm{~m})$ would have to be multiplied by a factor of 1.39 (1.17) with $90 \%$ uncertainty ranges of 1.24 to 1.58 (1.05 to 1.31) in order to account for thSLR contributions from deeper levels. Half $(50 \%)$ of the multi-model total expansion originates from depths below $490 \pm 90 \mathrm{~m}$, with the range indicating scenario-to-scenario variations. To support the development of surrogate methods to project thermal expansion, we calibrate two simplified parameterizations against CMIP5 estimates of thSLR: one parameterization is suitable for scenarios where hemispheric ocean temperature profiles are available, the other, where only the total ocean heat uptake is known (goodness of fit: \pm 5 and $\pm 9 \%$, respectively).
\end{abstract}

\section{Introduction}

Sea level rise due to anthropogenic climate change constitutes a major impact to the world's coastlines, low-lying deltas and small island states. The climate system is warming and during the relatively well-sampled recent 40 -year period (1971-2010) the world ocean absorbed $93 \%$ of the Earth's radiative energy excess, whereby $70 \%$ of the net oceanic heat gain is found in depths above and $30 \%$ below $700 \mathrm{~m}$ (Rhein et al., 2013). As the ocean takes up heat, the thermal expansion of seawater is a major driver behind sea level rise (SLR). Church et al. (2013a) note that $40 \%$ of the observed global mean SLR over 1971-2010 can be attributed to thermal expansion. This volumetric response of the ocean to temperature changes is expressed by its thermal expansion coefficient $\alpha$ (e.g., Griffies et al., 2014) and is due to nonlinearities of the thermodynamic properties (potential temperature, $\Theta$, salinity, $S$, and pressure, $p$ ) in the equation of state of seawater density, $\rho$ (e.g., Jackett et al., 2006). Thus, changes in heat fluxes at the sea surface and heat redistribution in the ocean's interior by advection, eddies and diffusion, lead to non-zero temperature differences altering the sea level even if the global mean potential temperature changes equal zero (Lowe and Gregory, 2006; Piecuch and Ponte, 2014). In turn, processes in the interior ocean cause spatial patterns of ocean heat uptake at the sea surface which define regional and global warming rates (Rose et al., 2014). Sea level is often defined as the height of the sea surface relative to the geoid - the surface of equal gravitational potential of a hypothetical ocean at rest - also called the geocentric sea level according to Church et al. (2013a). Therefore sea level changes integrate all volume changes of the world ocean. 
Aside from thermal expansion, SLR is also induced by changes in ice-sheet as well as glacier mass and land water storage that combined amounts to $60 \%$ of the observed global mean SLR over 1971-2010 (Church et al., 2013a). Over the last century, these mass changes in the ocean (termed "barystatic" sea level changes by Gregory et al., 2013a) together with ocean's thermal expansion have been the main contributors to global mean SLR. Some other influences, such as salinity variations associated with freshwater tendencies at the sea surface and redistributed in the ocean's interior have a negligible effect on seawater density and thus sea level changes on the global scale (e.g., Lowe and Gregory, 2006); on regional to basin scales, however, the role of salinity should not be neglected in sea level studies (e.g., Durack et al., 2014a). In the long term, the mass contribution might become substantially larger than thermal expansion contribution to SLR because of the larger efficiency of land-ice melting for a given amount of heat (Trenberth and Fasullo, 2010). However, the current climate models of the Coupled Model Intercomparison Project Phase 5 (CMIP5) do not include land ice-sheet discharge dynamics and their contributions to the global mean SLR budget (Church et al., 2013b). Furthermore, simulating land ice-sheet discharge dynamics from the Antarctic ice sheets might translate into large uncertainties in climate models, since non-linear processes may be triggered that could alter the sea level rise contribution dramatically (e.g., Joughin et al., 2014; Rignot et al., 2014; Mengel and Levermann, 2014). Since the beginning of the satellite altimetry era in 1993, the contribution of thermal expansion to global mean SLR is estimated to be $34 \%$ (observations) and $47 \%$ (simulations), respectively (see Table 13.1 in Church et al., 2013a). Down to the present day, the observed SLR contribution from thermal expansion is limited in the space and time dimension: available observed long-term (decadal) time series of thermosteric sea level rise (thSLR) are mainly globally averaged values using different spatio-temporal interpolation/reconstruction methods and cover the upper $2000 \mathrm{~m}$ at maximum (Domingues et al., 2008; Ishii and Kimoto, 2009; Levitus et al., 2012). Observed contributions to thSLR from depths below $2000 \mathrm{~m}$ are assumed to increase monotonically and linearly in time (Purkey and Johnson, 2010; Kouketsu et al., 2011). For details on the spatial as well as temporal coverage and quality of oceanic temperature measurements that underlie thSLR estimates we refer to Abraham et al. (2013) and references therein.

The objective of the present study is both to complement observed and existing simulated thSLR estimates in a number of ways and to enable the development of surrogate techniques for long-term thSLR projections. We begin by introducing the observed and simulated data sets as well as the method to arrive at thSLR estimates. Subsequently, we calculate the simulated thermal expansion over the entire ocean grid for a number of CMIP5 models that have not published those time series yet. Sections 3 and 4 present both the ex- tended CMIP5 thSLR (zostoga) data set and depth-dependent results that can complement upper ocean layer observations. Sections 5 and 6 investigate hemispheric and global averages of calibrated thSLR mimicking CMIP5 estimates. In Sect. 7 we discuss and summarize our results focussing on the extent to which the observations might underestimate the contribution to thSLR from depths below the main thermocline.

\section{Methods and models}

The volumetric response to changes in the ocean's heat budget, the thermosteric sea level, $\eta_{\Theta}$, at any horizontal grid point and any arbitrary time step is defined by the vertically integrated product of the thermal expansion coefficient, $\alpha$, and the potential temperature deviation from a reference state, $\Theta_{\exp }-\Theta_{\text {ref }}$,

$$
\eta_{\Theta}(x, y, t)=\int_{-H}^{0} \alpha\left(\Theta_{\exp }-\Theta_{\mathrm{ref}}\right) \mathrm{d} z,
$$

where the spatial 3-D thermal expansion coefficient, $\alpha$ is defined by

$$
\alpha=\frac{-1}{\rho\left(S_{\mathrm{ref}}, \Theta_{\mathrm{ref}}, p\right)} \frac{\rho\left(S_{\mathrm{ref}}, \Theta_{\mathrm{exp}}, p\right)-\rho\left(S_{\mathrm{ref}}, \Theta_{\mathrm{ref}}, p\right)}{\left(\Theta_{\mathrm{exp}}-\Theta_{\mathrm{ref}}\right)} .
$$

CMIP5 publishes time series of global mean (0-D) $\eta_{\Theta}$, called zostoga and represents the integral value of ocean's thermal expansion, $\alpha\left(\Theta_{\exp }-\Theta_{\text {ref }}\right)$, at each grid point, over the entire ocean volume. For the majority of the fully coupled climate models, sea level changes due to net gain of heat need to be diagnosed offline as a result of using the Boussinesq approximation, conserving ocean's volume and not mass (Greatbatch, 1994). Here, we derive global mean yearly depth profiles of thermal expansion by using independent $\Theta$ and $S$ prognostics of CMIP5 model simulations in Eq. (2).

In order to derive thermal expansion estimates, and zostoga, from hemispherically or globally averaged vertical temperature profiles, rather than from sparsely observed and computationally expensive spatial 3-D fields of temperature, salinity and pressure, we use a simplified parameterization of a thermal expansion coefficient, $\alpha_{1.5}$, as a polynomial of $\Theta$ and $p$ :

$$
\begin{aligned}
\alpha_{1.5} & =\left(c_{0}+c_{1} \Theta_{0}(12.9635-1.0833 p)\right. \\
& -c_{2} \Theta_{1}(0.1713-0.019263 p) \\
& \left.+c_{3} \Theta_{2}(10.41-1.1338 p)+c_{4} p-c_{5} p^{2}\right) \times 10^{-6},
\end{aligned}
$$

with $\Theta_{0}=\Theta_{\text {exp }}, \Theta_{1}=\Theta_{0}^{2}$ and $\Theta_{2}=\Theta_{0}^{3} / 6000$ and calibration parameters $c_{n=0-5}$. This polynomial algorithm is based on a simplification of the equation of state of seawater given in Gill (1982), assuming a constant salinity of 35 PSS-78. It is, for example, included in the reducedcomplexity Model for the Assessment of Greenhousegas Induced Climate Change (MAGICC) (Raper et al., 
1996; Wigley et al., 2009; Meinshausen et al., 2011). The depth profile, $z$, is expressed by the pressure profile $p=$ $0.0098(0.1005 z+10.5 \exp ((-1.0) z / 3500)-1.0)$, assuming a mean ocean depth of $3500 \mathrm{~m}$ and a mean maximum ocean depth of $6000 \mathrm{~m}$ in Eq. (3). As a first step, we use timedependent vertical global and hemispheric profiles of $\Theta$ from the CMIP5 models to test the reliability of thermal expansion estimates based on this simplified approach (Eq. 3). With these time series of vertical temperature profiles we calibrate $\alpha_{1.5}$ in Eq. (3) with calibration parameters $c_{n}$ against globally and hemispherically averaged vertical profiles of $\alpha$ in Eq. (2) (using squared differences as goodness-of-fit statistic).

We name this parameterization the 1.5-D simplification, as it uses two hemispherically averaged depth profiles. In addition, we use the CMIP5 data to estimate the zero-dimensional (0-D) thermal expansion coefficient $\alpha_{0}$. Divided by ocean's specific heat capacity, reference density and area, it gives the "expansion efficiency of heat" (in $\mathrm{m} \mathrm{YJ}^{-1}, 1 \mathrm{YJ} \equiv 10^{24} \mathrm{~J}$ ) and allows the comparison of thermal expansion from models with different spatial dimensions (Russell et al., 2000). This constant quantifies the proportionality between global mean thSLR and ocean heat uptake (OHU) (cf. Kuhlbrodt and Gregory, 2012).

We examine a broad range of CMIP5 scenarios, namely the historical (post-1850) climate simulations, the idealized $1 \% \mathrm{CO}_{2}$ per year increase (1pctCO2) and the response to abrupt $4 \times$ pre-industrial $\mathrm{CO}_{2}$ increase (abrupt $4 x \mathrm{CO} 2$ ). But as we aim to complement observed and existing simulated thSLR estimates and to design surrogate techniques to project long-term thSLR, we focus on the four scenarios defining future change in radiative forcing, namely rcp2.6, rcp4.5, rcp6.0 and rcp8.5. These scenarios specify four greenhouse gas concentration trajectories and their Representative Concentration Pathways (RCP). They are named after the amount of radiative forcing (in $\mathrm{W} \mathrm{m}^{-2}$ ) realized in the year 2100 relative to values of the pre-industrial (pre1850) control scenario (piControl) (for details see Taylor et al., 2012; Moss et al., 2010, and Table S1 in the Supplement). However, recent literature suggests that the rapid adjustment primarily due to clouds generates forcing variations that cause differences in the projected surface warming among the CMIP5 models even if radiative forcing is equally prescribed for each individual CMIP5 model (Forster et al., 2013).

Independent of the model and estimation method, a "full linear drift" is removed from all simulated thermosteric sea level time series, zostoga and temperature time series by subtracting a linear trend based on the entire corresponding ( $p i$ Control) scenario in order to allow for comparison with observational time series. For our globally and hemispherically averaged thSLR time series the sensitivity to the method of drift correction is less than $1 \%$ due to small low-frequency (inter-annual to inter-decadal) variability present in the evolution of this integral oceanic property. This contrasts the large low-frequency variability, e.g. in the sea surface tem- perature evolution (Palmer et al., 2009). For details about methods of climate drift correction in CMIP5 models see Taylor et al. (2012), Sen Gupta et al. (2013) and the supplementary by Church et al. (2013a). Additionally, we correct the historical time series by adding the suggested thSLR trend of $0.1 \pm 0.05 \mathrm{~mm} \mathrm{yr}^{-1}$ by Church et al. (2013b) to take into account that the CMIP5 piControl scenario might be conducted without volcanic forcing and thus underestimate the oceanic thermal expansion in the historical scenario (Gregory et al., 2013b). The adjustment of global mean SLR to changes in ocean mass is fast and linear (Lorbacher et al., 2012); thus in the longer term, impacts of changing ocean mass on SLR may well become the primary contribution to the trend in SLR. For projected time series beyond the historical simulations, we use the $r c p 4.5$ simulations consistent with Church et al. (2013a).

\section{Extended CMIP5 zostoga data set}

For CMIP5 models that report zostoga, we calculate the RMSE between published zostoga values and our recalculated values based on the provided $\Theta$ and initial $S$ depth profiles. Averaged over all CMIP5 models and scenarios and normalized by the mean zostoga value, the RMS-error amounts to $\pm 1 \%$, providing confidence that our 3-D equation of state implementation is consistent with those of CMIP5 modelling groups. As not all CMIP5 models that provide $\Theta$ and $S$ also provide zostoga, our recalculated data set comprises $30 \%$ more modelled zostoga time series than currently published within CMIP5 (compare Table S1 and Fig. 1a, e.g., to Fig. 13.8 in Church et al., 2013a). These complementing zostoga time series contribute $50 \%$ more CMIP5 models to multi-model ensemble thSLR estimates than previously used by Church et al. (2013a); they are available at http://climate-energy-college.net/ complementing-thermosteric-sea-level-rise-estimates and as Supplement. Time series of zostoga published by the individual model groups are available, e.g., here http://pcmdi9.1lnl. gov/esgf-web-fe.

For the RCPs, our extended data set implies a maximum thSLR of $0.4 \mathrm{~m}$ for the $21 \mathrm{st}$ century. For $r c p 8.5$ in 2081-2100 relative to 1986-2005, the projected model median thSLR and its $90 \%$ confidence interval amounts to $0.28 \pm 0.06 \mathrm{~m}$ (see Table 1 for more scenario results). The corresponding thSLR published by Church et al. (2013a) is $0.27 \pm 0.06 \mathrm{~m}$. For all four RCP scenarios, our results indicate that previous CMIP5 multi-model ensemble estimates by Church et al. (2013a) have been robust, despite being based on $30 \%$ less models than used here (Tables $1, \mathrm{~S} 1$ and Table 13.5 in Church et al., 2013a). The idealized scenarios reveal a concave thSLR up to $0.4 \mathrm{~m}$ in $1 p c t C O 2$ and a convex sea level rise up to $0.8 \mathrm{~m}$ in abrupt $4 x \mathrm{CO} 2$ over the first 100 years. 
Table 1. Median and its $90 \%$ confidence interval for projections of global mean thSLR (in m) in 2046-2065 and 2081-2100 relative to 1986-2005 as well as in year 2100 relative to year 1900 for the four RCP scenarios.

\begin{tabular}{llllll}
\hline $\begin{array}{l}\text { Period } \\
\text { scenario }\end{array}$ & $1986-2005$ & $2046-2065$ & $2081-2100$ & 2100 & $\begin{array}{l}2081-2100 \\
\text { IPCC-AR5 }\end{array}$ \\
\hline Historical & $0.04[0.01$ to 0.07$]$ & & & & \\
rcp2.6 & & $0.10[0.06$ to 0.13$]$ & $0.15[0.10$ to 0.20$]$ & $0.19[0.14$ to 0.24$]$ & $0.14[0.10$ to 0.18$]$ \\
rcp4.5 & & $0.11[0.08$ to 0.14$]$ & $0.19[0.14$ to 0.24$]$ & $0.24[0.19$ to 0.29$]$ & $0.19[0.14$ to 0.23$]$ \\
rcp6.0 & & $0.11[0.08$ to 0.14$]$ & $0.20[0.15$ to 0.25$]$ & $0.26[0.21$ to 0.32$]$ & $0.19[0.15$ to 0.24$]$ \\
rcp8.5 & & $0.13[0.10$ to 0.16$]$ & $0.28[0.22$ to 0.34$]$ & $0.36[0.29$ to 0.42$]$ & $0.27[0.21$ to 0.33$]$ \\
\hline
\end{tabular}

\section{Complementing observations}

For the upper $700 \mathrm{~m}$, our extended CMIP5 multi-model median rate of thSLR and its standard deviation globally amounts to $0.57 \pm 0.03 \mathrm{~mm} \mathrm{yr}^{-1}$ from 1971 onward to 2010 (Figs. $1 \mathrm{~b}$ and S3b in the Supplement) and is similar to the observed arithmetic mean $0.53 \pm 0.02 \mathrm{~mm} \mathrm{yr}^{-1}$ of the three individual trends $0.63 \pm 0.02 \mathrm{~mm} \mathrm{yr}^{-1}$ (Domingues et al., 2008), $0.45 \pm 0.02 \mathrm{~mm} \mathrm{yr}^{-1}$ (Ishii and Kimoto, 2009) and $0.50 \pm 0.03 \mathrm{~mm} \mathrm{yr}^{-1}$ (Levitus et al., 2012) (cf. Fig. 13.4 in Church et al., 2013a). For the same period, around half of the models underestimate the ocean's thermal expansion in simulations, even after the correction for missing volcanic forcing in the piControl scenario (Gregory et al., 2013b). Nevertheless, the majority of the historical scenarios capture the main volcanic eruptions in the years 1963 (Agung), 1982 (El Chichón) and 1991 (Pinatubo) with a sea level drop 12 years later. Generally, differences in the observed and interannual variability suggest that the underlying spatial patterns of interannual thermosteric sea level variability are different (Fyfe et al., 2010). For the altimetry period (19932010), our multi-model median is $1.45 \mathrm{~mm} \mathrm{yr}^{-1}$, with 1.02 to $1.97 \mathrm{~mm} \mathrm{yr}^{-1}$ as $90 \%$ uncertainty, taking into account the contribution of thermal expansion to the global mean SLR from the entire ocean depth. This rate of thSLR equals the corresponding rate of $1.49 \mathrm{~mm} \mathrm{yr}^{-1}$ and its uncertainty range of 0.97 to $2.02 \mathrm{~mm} \mathrm{yr}^{-1}$ listed in Table 13.1 by Church et al. (2013a) and confirms again the robustness of simulated thSLR estimated presented by Church et al. (2013a) with $30 \%$ less models for a multi-model estimate than used here.

The model median contribution to thSLR from the layer between 700 and $2000 \mathrm{~m}$ suggests a slight underestimation of the observational data for the period 2005-2013 (Figs. 1c and S3c). For ocean depths below $2000 \mathrm{~m}$, the model median trend for the years $1990-2000$ of $0.11 \mathrm{~mm} \mathrm{yr}^{-1}$ in the historical scenario seems to reliably represent the thSLR contribution which Purkey and Johnson (2010) estimated (Figs. 1d and S3d). For an ocean warming occurring at a depth below $3000 \mathrm{~m}$ Kouketsu et al. (2011) estimate a similar thSLR over a 40-year period; based on observed and assimilated data it amounts to 0.10 and $0.13 \mathrm{~mm} \mathrm{yr}^{-1}$, respectively. For the upper $2000 \mathrm{~m}$, the depth profiles of thermodynamic properties across CMIP5 models are largely aligned with observa- tional depths profiles for $\Theta$ and $S$ of the modern day (20052013) ocean provided by the Argo program (Roemmich and Gilson, 2009); the same is true for the derived thermal expansion coefficient (see Fig. 2 and depth profiles of potential temperatures in the piControl scenario by Kuhlbrodt and Gregory, 2012). The simulated salinity profile shows the observed maximum at around $200 \mathrm{~m}$ that reflects evaporation zones and a minimum at around $500 \mathrm{~m}$ that reflects mode water regions. For depths below $500 \mathrm{~m}$, the model spread of $\Theta$ and $S$ amounts to $2{ }^{\circ} \mathrm{C}$ and 0.4 PSS-78, with only a few model outliers. Independent of the model and scenario, the thermal expansion coefficient $\alpha$ at the sea surface decreases from $4 \times 10^{-4}{ }^{\circ} \mathrm{C}^{-1}$ in tropical to near zero in polar regions and, globally averaged, shows the familiar concave vertical profile (e.g., Griffies et al., 2014) with a minimum around $1500 \mathrm{~m}$ (Fig. 2). The minimum global mean climatological value of $\alpha$ amounts to $1.3 \times 10^{-4}{ }^{\circ} \mathrm{C}^{-1}$ for the historical scenario and agrees well with the observed one. Averaged over the entire water column, $\alpha\left(1.56 \times 10^{-4}{ }^{\circ} \mathrm{C}^{-1}\right)$ compares well with the corresponding value from ocean-only simulations $\left(1.54 \times 10^{-4}{ }^{\circ} \mathrm{C}^{-1}\right.$, Griffies et al., 2014). In the Northern Hemisphere, $\alpha$ is $1 \%$ higher than in the Southern Hemisphere because average temperatures tend to be higher above $2000 \mathrm{~m}$ in the Northern Hemisphere (not shown). For details on the horizontal and vertical behaviour of $\alpha$ see, e.g., Griffies et al. (2014) and Palter et al. (2014).

Observed thSLR estimates with a vertical integration limit that is not the entire ocean depth due to data sparsity will need to be complemented by an approximation for the thSLR contributions originating by changes in deeper layers. Our CMIP5 analysis derives those deeper layer contributions as percentage shares of total thSLR across our range of scenarios (see multi-model median in Fig. 3). The contributions relevant to a global sea level budget clearly depend on the scenario and hence the atmospheric forcing. The higher the radiative forcing gradient of the scenario, the lower the contribution is from depths below $2000 \mathrm{~m}$. The stronger the warming signal in the ocean's upper layers the more enhanced the stratification is in the upper layers. The abrupt $4 x \mathrm{CO} 2$ scenario is noticeable where $90 \%$ of the thermal expansion is confined to the upper $700 \mathrm{~m}$ in the first 20 years and that the evolution of thSLR contributions from a depth below 

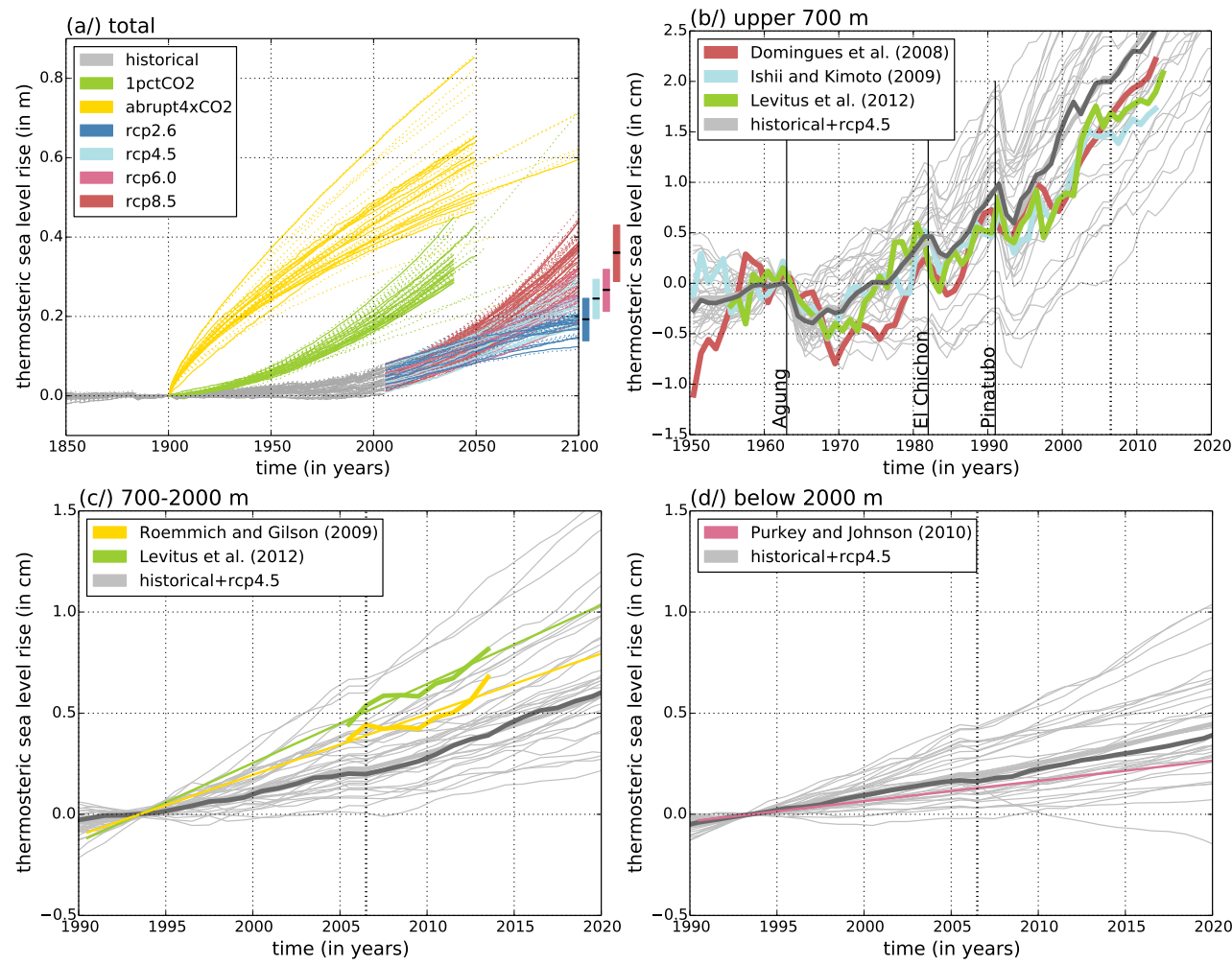

Figure 1. Time series of observed and simulated global mean yearly thSLR (in cm). (a) Simulated thSLR (zostoga) relative to year 1900 for seven CMIP5 scenarios: historical (31/47), 1pctCO2 (19/32), abrupt4xCO2 (17/30), rcp2.6 (18/26), rcp4.5 (27/40), rcp6.0 (13/20), rcp8.5 (27/40); the ratio in brackets indicates the number of models of published (solid lines) zostoga and recalculated (dashed lines) zostoga in this study based on simulated temperature and salinity fields. Bars indicate the thSLR of the four RCP scenarios in year 2100 (see also Table 1). (b) Observed contribution to yearly thermosteric sea level of the upper $700 \mathrm{~m}$ by Domingues et al. (2008), Ishii and Kimoto (2009) and Levitus et al. (2012) relative to year 1961 and corresponding simulated time series of the historical and $r c p 4.5$ scenarios, whereby the solid light (dark) grey lines represent the model mean (median). Observed contribution to yearly thermosteric sea level (in $\mathrm{cm}$ ) from layers (c) between 700 and $2000 \mathrm{~m}$ by Levitus et al. (2012) and Roemmich and Gilson (2009) and (d) below $2000 \mathrm{~m}$ by Purkey and Johnson (2010) relative to year 1993 (indicating the start of the satellite sea level altimetry period). Corresponding simulated time series are shown as in (b).

$2000 \mathrm{~m}$ (as share of total thSLR) shows an opposing trend compared to the 21 st century evolution of the multi-gas scenarios. Firstly, the idealized experiments are started from preindustrial control equilibrium conditions and hence miss the initial stratification and upper layer expansion between historical's start year (usually 1850) and the start year of our analysis (1900 for the historical and 2006 for the RCP scenarios) (cf. Russell et al., 2000). Secondly, the initial warming pulse in abrupt $4 x \mathrm{CO} 2$ is extreme: already within the first year of the model scenario, thermal expansion in the upper $300 \mathrm{~m}$ shows a clear increase in the global mean, for all CMIP5 models, and amounts to a magnitude of thermal expansion corresponding to the last 20 years (1986-2005) of the historical scenario (Figs. 2d, h and S3a). After 20 years, the thermal expansion for the abrupt4xCO2 scenario in this upper layer equals almost the thermal expansion of the rcp2.6 scenario at the end of the 21st century (not shown). Both characteristics of abrupt $4 x \mathrm{CO} 2$ define a large vertical temperature gradient between surface and deeper water almost instantaneously. Mixing and advection erodes this large vertical temperature gradient, so that after 90 years the contribution below $700 \mathrm{~m}$ increased to $33 \%$ and below $2000 \mathrm{~m}$ to $7 \%$. At the beginning of the 21 st century, the initial thSLR contribution for the four RCP scenarios shows high levels around $40 \%$ (20\%) for depth below $700 \mathrm{~m}(2000 \mathrm{~m})$ and then decreases in layers below $2000 \mathrm{~m}$. For the lower and intermediate forcing scenarios, $r c p 2.6$ and $r c p 4.5$, the $700 \mathrm{~m}$ upper layer's proportion decreases, too. In all multi-gas scenarios, the middle layer's share of total thSLR, i.e., between 700 and 2000 m (light-grey band in Fig. 3), tends to increase over the 21 st century. The explanation for this tendency of middle and deeper layer thSLR contributions to the total thSLR is likely related to multiple effects. The warming induced intensified stratification in the upper $700 \mathrm{~m}$ seems the obvious effect for the decreasing contributions from layers below $2000 \mathrm{~m}$. Additionally, we propose the effect of the cessation of sporadic volcanic forcing in the RCP scenarios compared to the historical simulations. Towards the end of the historical scenario, 

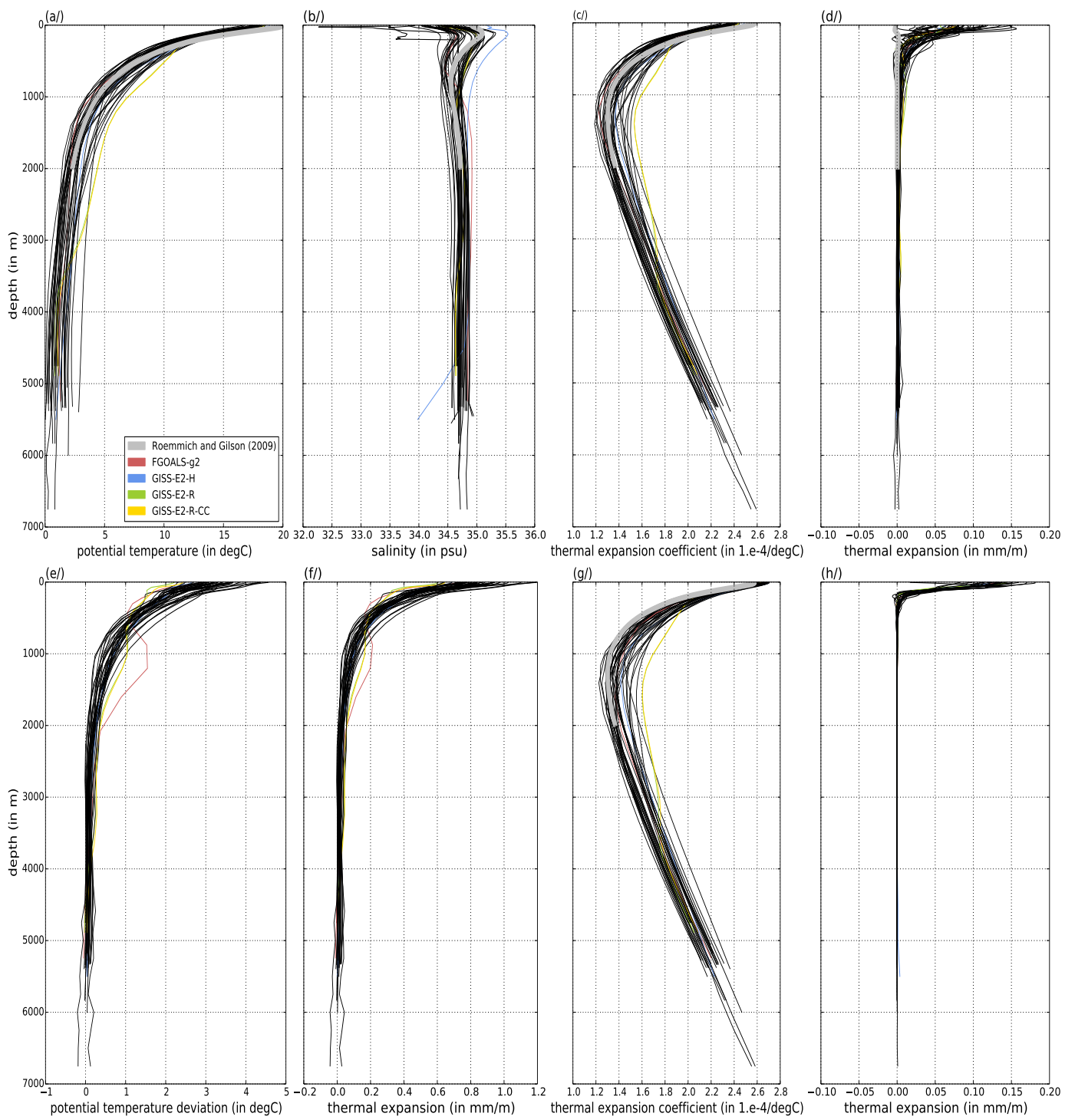

Figure 2. Global mean vertical profiles for all models of historical in year 1900 (upper panels, a-c), historical in year 2005 relative to year 1986 (d), rcp8.5 in year 2100 relative to the historical mean over 1986 to 2005 (lower panels, e-g) and abrupt4xCO2 within the first year (h): (a) potential temperature (in ${ }^{\circ} \mathrm{C}, 0$ to 20 ), (b) salinity (in PSS-78, 32 to 36) and (c) thermal expansion coefficient $\alpha$ (in $10^{-4}{ }^{\circ} \mathrm{C}^{-1}, 1.2$ to 2.8); (d) thermal expansion per layer (in $\mathrm{mm} \mathrm{m}^{-1},-0.1$ to 0.2 ), (e) temperature deviation (in ${ }^{\circ} \mathrm{C},-1$ to 5 ), (f) thermal expansion per layer (in $\mathrm{mm} \mathrm{m}^{-1},-0.2$ to 1.2 ) and (g) thermal expansion coefficient $\alpha$ (in $10^{-4}{ }^{\circ} \mathrm{C}^{-1}, 1.0$ to 2.8 ), (h) thermal expansion per layer (in mm $\mathrm{m}^{-1}$, -0.2 to 1.2). Observed profiles (grey lines) are based on the Argo data as an average over the period 2005 to 2013 , except for the thermal expansion in (d). Model outliers are indicated in (a).

i.e., the start of the RCP scenarios, the volcanic forcing in historical might suppress the thermal expansion of middle layers $(700-2000 \mathrm{~m})$ and might therefore lead to a certain rebound effect of the middle layer thSLR contributions in the mid-21st century (cf. Fig. S3). However, for the multigas scenarios, the overall 21 st century multi-model median thSLR contribution of the deep ocean is $39 \%$ from depth below $700 \mathrm{~m}$ with 24 to $58 \%$ as $90 \%$ uncertainty and $17 \%$ from depths below $2000 \mathrm{~m}$ with 5 to $31 \%$ as $90 \%$ uncertainty (see Fig. 3a-d). The contributions for the RCP refer- ence period (1986-2005, Church et al., 2013a) taken from the historical simulations are $46 \%$ [21 to $73 \%$ ] (and $21 \%$ [4 to $44 \%$ ]) (Fig. 3e).

\section{The 1.5-D parameterization}

We obtain six calibration parameters $c_{n}$ for each CMIP5 model through our optimization scheme that minimizes the RMS errors from iteration to iteration. When comparing our extended set of CMIP5 thSLR (zostoga) time series with 

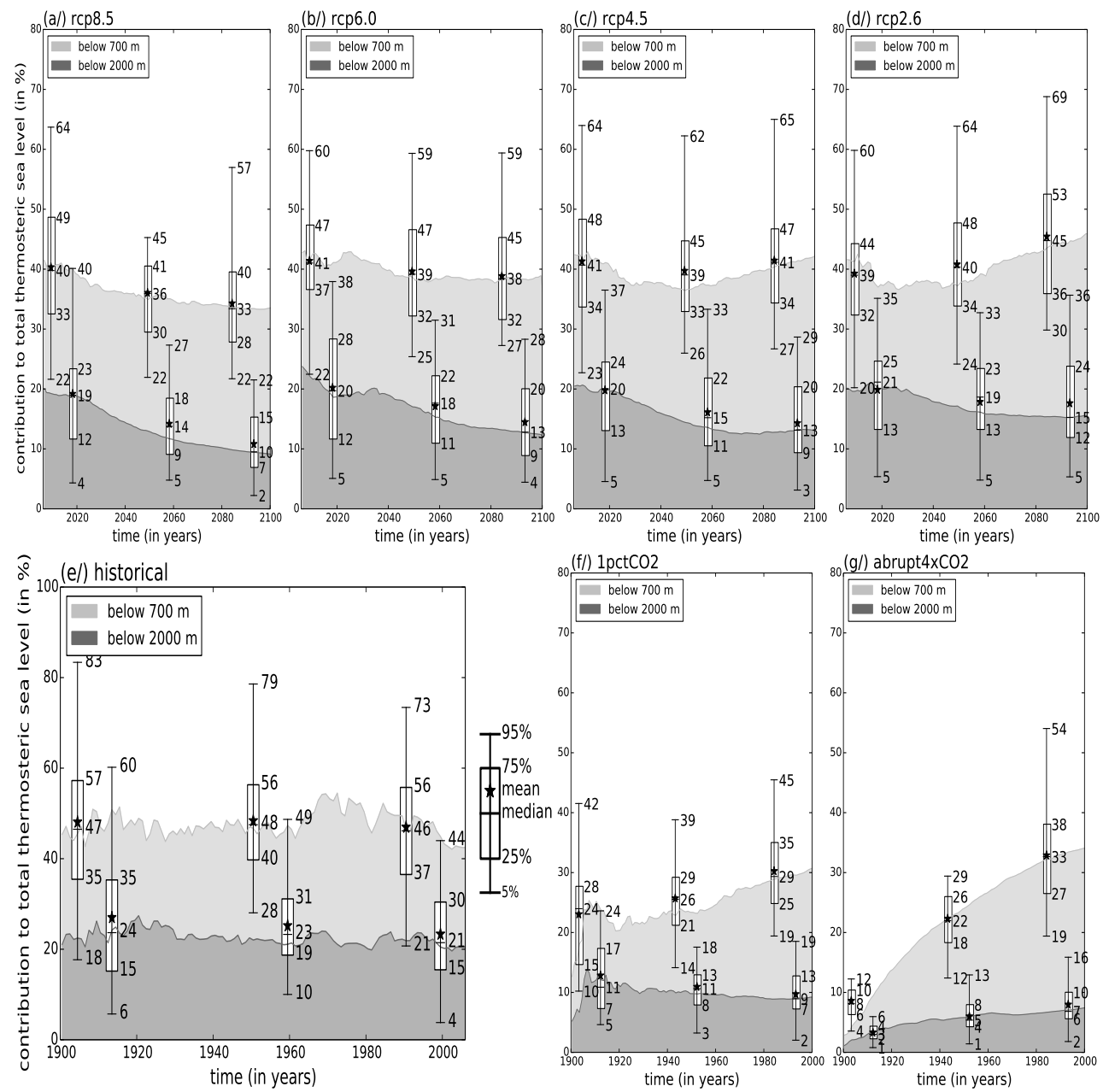

Figure 3. Model median percentage contribution to global mean thSLR for the entire water column from depths below $700 \mathrm{~m}$ (light grey) and below $2000 \mathrm{~m}$ (dark grey) for the historical scenario, for projections for the four RCP scenarios and the two idealized $\mathrm{CO}_{2}$ scenarios derived from Eq. (2). Whisker plots quantify the temporal average distribution of the contribution to thSLR of the first 20 years, the entire time series and the last 20 years, respectively: 2006-2025/2006-2100/2081-2100 for RCPs (a-d); 1901-1920/1900-2005/1981-2005 for the historical scenario (e); and 1-20/1-100/81-100 for the 1pctCO2 and abrupt4xCO scenarios (f, g). Bars and whiskers represent the 25-75 and 5-95 \% uncertainties of the median, respectively; the central mark of the bar indicates the model median, the asterisk the model mean.

the thSLR time series obtained by using potential temperatures and standard pressure profiles with Eq. (3), we then obtain an average error of $\pm 5 \%$, ranging between 1 and $17 \%$ across the CMIP5 model suite (see Table S2). The hemispherically averaged percentage contributions to thSLR based on the 1.5-D simplified thermal expansion coefficient (Eq. 3) for all seven scenarios compare well with our extended CMIP5 data set (Fig. 4). The thSLR contribution from depths below $2000 \mathrm{~m}$ is larger in the Southern Hemisphere than in the Northern Hemisphere. This might be due to model-dependent mixing rates forming Antarctic bottom water, that Wang et al. (2014) assigned to CMIP5 model biases in the Southern Ocean's sea surface temperature. Strong outliers (values far outside the whiskers and the $90 \%$ confidence interval) are found in the depth range below the main thermocline between 700 and $2000 \mathrm{~m}$ independent of the scenario and spatial averaging.

\section{The 0-D parameterization}

Our findings complement Kuhlbrodt and Gregory (2012) who analyzed the "expansion efficiency of heat" as constant of proportionality between thSLR and OHU for the $1 p c t C O 2$ scenarios and concluded that model differences in the stratification below the main thermocline largely explain the differences between the individual models. Based on the original CMIP5 ensemble with $30 \%$ less CMIP5 models than used here, the constant for global mean (0-D) time series estimated by Kuhlbrodt and Gregory (2012) amounts to $0.11 \pm 0.01 \mathrm{~m} \mathrm{YJ}^{-1}$. Our median and its $90 \%$ confidence in- 

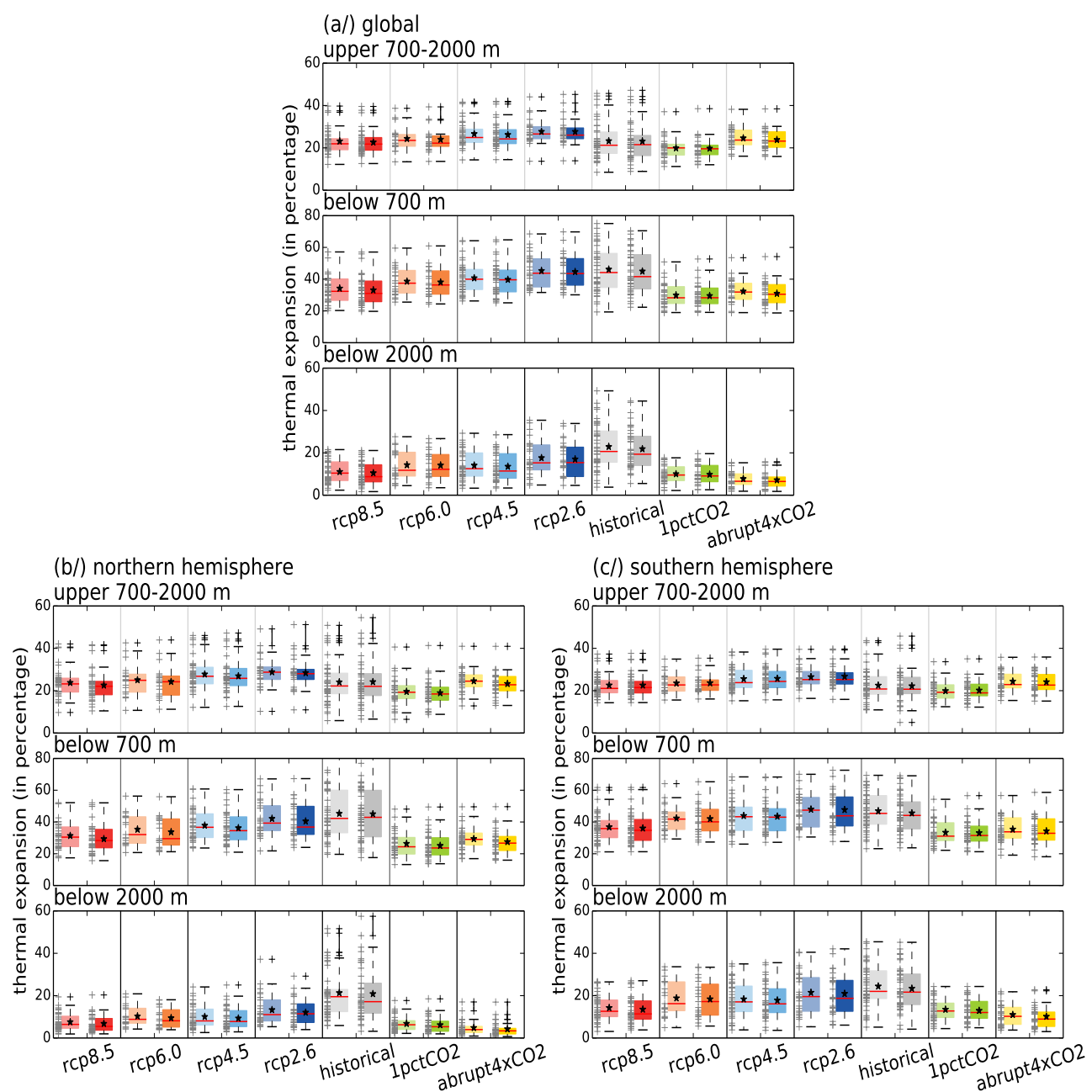

Figure 4. Whisker plots of percentage thermal expansion from the layers between 700 and $2000 \mathrm{~m}$, below $700 \mathrm{~m}$ and below $2000 \mathrm{~m}$, respectively, relative to the total thermal expansion integrated over the entire water column, for seven scenarios. Thermal expansion estimates are derived from Eq. (2) (left bar) and Eq. (3) (right bar) used in simpler climate models (here with the optimized calibration parameters in Table S2) and are based on (a) globally, (b) northern and (c) southern hemispherically averaged vertical potential temperature profiles, followed by a temporal averaging over the entire time series (see Fig. 3). Bars and whiskers represent the 25-75 and 5-95\% uncertainties of the median, respectively; the central mark of the bar indicates the model median, the asterisk the model mean. The number of models available for these statistical estimates are crosses on the left of the box, at which crosses above and below the whiskers indicate model outliers.

terval amounts to $0.12 \mathrm{~m} \mathrm{YJ}^{-1}[0.10$ to 0.14$]$ as integral over the entire water depths, $0.14 \mathrm{~m} \mathrm{YJ}^{-1}[0.12$ to 0.15$]$ for the upper $700 \mathrm{~m}$ and $0.10 \mathrm{~m} \mathrm{YJ}^{-1}[0.08$ to 0.11$]$ below $700 \mathrm{~m}$ (Table S4.1). The constant depends on the 3-D pattern of heat redistribution with the main contribution arising from the upper $700 \mathrm{~m}$. This pattern depends in equal measure on the individual model and on the scenario for a given model (see Table S4.1 and S4.2). Our 0-D approach results in a normalized difference between thSLR estimates based on a 3-D (in Eq. 2) and spatially constant (0-D) thermal expansion coefficients of $9 \%$.

\section{Discussion and summary}

The present study aims to complement our quantitative understanding of thSLR using CMIP5 results. Firstly, based on CMIP5 temperature and salinity data for a range of scenarios, we calculate a compilation of thermal expansion time series that comprise $30 \%$ more simulations than currently published within CMIP5. This accounts for $50 \%$ more models in the multi-model ensemble estimates than used by Church et al. (2013a). However, our results confirm the robustness of these previous CMIP5 multi-model thSLR estimates.

Secondly, we quantify the thSLR contribution from the entire ocean depth in order to complement observational estimates that are primarily available for the upper ocean layers 

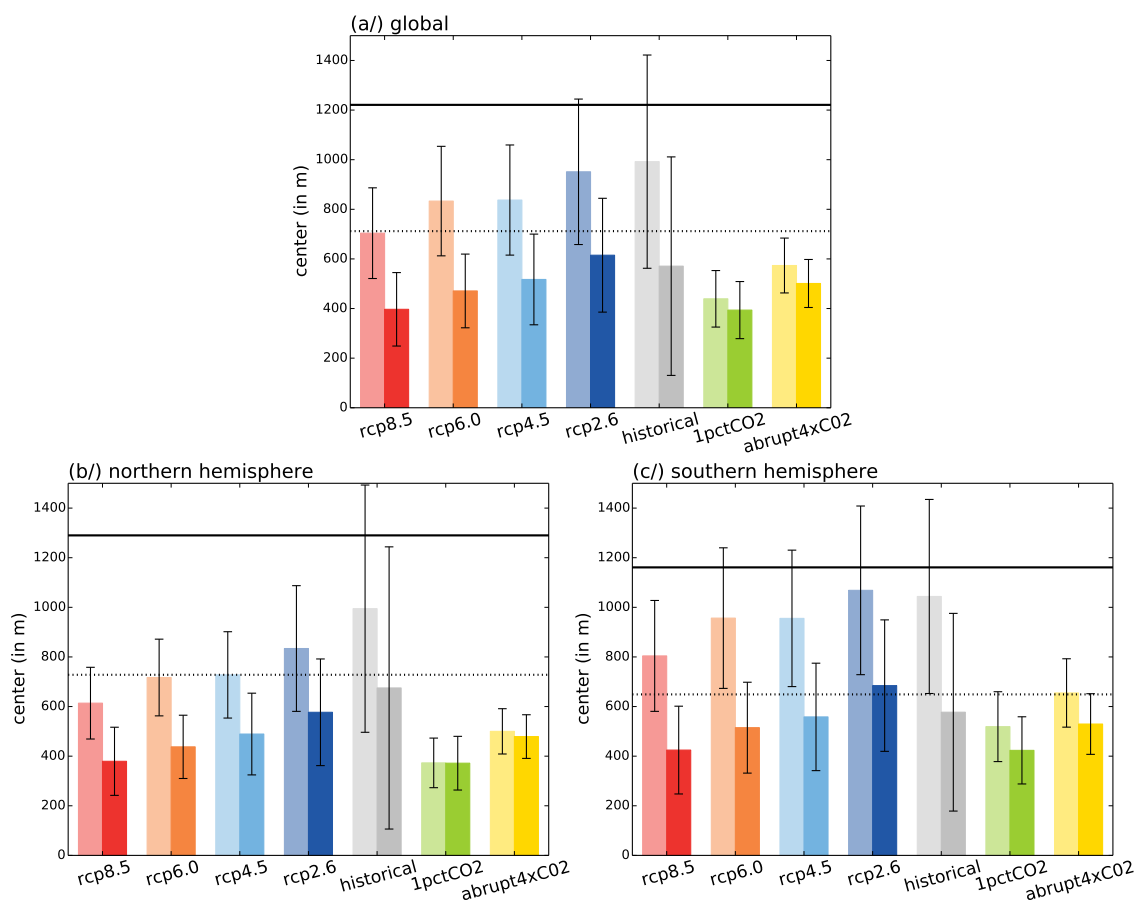

Figure 5. CMIP5 multi-model mean depth and standard deviation (in m) where the individual model mean (left bar) and median (right bar) depth of thSLR originates for the four RCP scenarios, as well as the historical scenario and the two idealized $\mathrm{CO}_{2}$-forcing scenarios. Thermal expansion estimates are derived from Eq. (2) based on (a) globally, (b) northern and (c) southern hemispherically averaged vertical potential temperature profiles, followed by a temporal averaging over the last 20 years (see Figs. 3 and 4). Table S5 summarizes the estimates. The horizontal solid (dashed) line indicates the mean (median) depth of thSLR based on climatological temperature and salinity profiles (Boyer et al., 2013).

down to $700 \mathrm{~m}$ (cf. Domingues et al., 2008). Sparse observational evidence points to non-significant contributions to global mean thSLR from depths below $2000 \mathrm{~m}$ during 2005 to 2013 (Llovel et al., 2014). Our results suggest that 21st century thSLR estimates derived solely based on observational estimates from the upper $700 \mathrm{~m}$ would have to be multiplied by a factor of 1.39 (with a $90 \%$ uncertainty range of 1.24 to 1.58 ) in order to be used as approximation for total thSLR originating from the entire water column. Correspondingly, our CMIP5 model analysis suggests that partial thSLR contribution based on hydrographic measurements from the upper $2000 \mathrm{~m}$ can be expected to account already for around $85 \%$ of the total thSLR and consequently have to be multiplied only by 1.17 (with a $90 \%$ uncertainty range of 1.05 to 1.31$)$. In fact, our results indicate that half $(50 \%)$ of the thSLR contributions can come from depths below $570 \mathrm{~m}$ in the historical simulations and from slightly shallower levels $(490 \pm 90 \mathrm{~m})$ in the future RCP scenarios, when averaged across the last 20 years of the scenario period (Fig. 5 and Table S5). Here, we define "half-depth" as the median of the depths distribution of OHU and thSLR contributions. We find that those "half-depths" are located within the thermocline. The OHU half-depth is around $100 \mathrm{~m}$ deeper than the thSLR half-depth due to nonlinearities in the seawater equation of state (not shown). Furthermore, those half-depths seem to be deeper in the Southern than in the Northern Hemisphere because the layers above $2000 \mathrm{~m}$ are warmer in the Northern Hemisphere and less stratified below the main thermocline. The recent study by Durack et al. (2014b) corroborates the relevance for hemispheric partitioning of model results to adjust for the poor sampling of the Southern Hemisphere's upper ocean temperatures. The mean depths are 100 (300) m lower than the medians for the idealized (RCP) scenarios and $400 \mathrm{~m}$ for the historical scenario (Table S5). This indicates a positive skewness of the vertical distribution of thermal expansion because of its long tail towards depths below $700 \mathrm{~m}$. For climatological temperature and salinity profiles (Boyer et al., 2013), the difference between the mean $(1200 \mathrm{~m})$ and median $(700 \mathrm{~m})$ depth is even greater compared to our model diagnostic results of the historical scenario. This can be explained by a reduced vertical temperature gradient within the main thermocline and a weaker stratification above the main thermocline induced by the absent end of 20th-century warming in the climatological profiles. In case of the historical scenario, the difference between mean and median depth of thermal expansion shows that the amount of thSLR due to the externally forced warming during the period 1986-2005 is small compared to the underlying interannual variability that is generated by the internal variability of ocean dynamics (Palmer et al., 2009; Palter et al., 2014). However, these find- 
ings highlight the importance of the thSLR contribution from deeper ocean layers (e.g., Palmer et al., 2011). Present and projected thSLR is not predominantly $(>50 \%)$ attributable to the layers above the depth of $700 \mathrm{~m}$, the depth most observational based estimated are still limited to (Domingues et al., 2008; Ishii and Kimoto, 2009; Levitus et al., 2012).

Lastly, in order to support the development of surrogate methods to project thermal expansion, we calibrate two simplified parameterizations against CMIP5 estimates of thSLR: one parameterization is suitable for scenarios where hemispheric ocean temperature profiles are available (1.5-D approach), the other, where only the total OHU (0-D approach) is known. Generally, expanding a mass of warm, salty subtropical water is more efficient for a given temperature increase than a mass of cold, fresh subpolar water for the same temperature increase. In upper tropical waters a warming signal persists longer than in upper high-latitude waters due to the weaker, temperature-dominated stratification in higher latitudes, except in the Southern Ocean around Antarctica where salinity changes play a fundamental role in determining the strength of stratification (Bindoff and Hobbs, 2013; Rye et al., 2014). Our diagnosis of CMIP5 profiles confirms the large variations in $\alpha$, the 3-D thermal expansion coefficient, due to strong meridional (not shown) and vertical density gradients originating from strong temperature gradients (see Eq. 2 and Fig 2). These strong vertical as well as meridional gradients in the thermal expansion efficiency raise the question whether simplified approaches that collapse either the meridional component (our 1.5-D simplification) or both dimensions (the 0-D approach) are sufficiently reliable. The introduced errors of $\pm 5 \%$ (1.5-D) and $\pm 9 \%$ (0-D) compared to the CMIP5 data based on the entire ocean grid, suggest that the simplifications are sufficiently accurate for long-term SLR projections, when other uncertainties (land ice-sheet response, climate sensitivity or radiative forcing (e.g., Hallberg et al., 2013) dominate the final result.

\section{The Supplement related to this article is available online at doi:10.5194/gmd-8-2723-2015-supplement.}

Author contributions. All authors contributed to designing and writing the text. K. Lorbacher conducted the analysis and drafted the manuscript.

Acknowledgements. We thank Dimitri Lafleur for his valuable and helpful comments on the manuscript. We acknowledge the World Climate Research Programme's Working Group on Coupled Modelling, which is responsible for CMIP, and we thank the climate modelling groups (listed in Table S1 of this paper and based on http: //cmip-pcmdi.llnl.gov/cmip5/docs/CMIP5_modeling_groups.pdf) for producing and making available their model output. For CMIP the US Department of Energy's Program for Climate Model Diagnosis and Intercomparison provides coordinating support and led development of software infrastructure in partnership with the Global Organization for Earth System Science Portals. Observational data by Domingues et al. (2008), Ishii and Kimoto (2009), Levitus et al. (2012) and Roemmich and Gilson (2009) are provided at http://www.cmar.csiro.au/sealevel/sl_data_cmar.html, https://atm-phys.nies.go.jp/ ism/pub/ProjD, http://www.nodc. noaa.gov/OC5/3M_HEAT_CONTENT/basin_tsl_data.html and http://sio-argo.ucsd.edu/RG_Climatology.html, respectively.

Edited by: R. Marsh

\section{References}

Abraham, J. P., Baringer, M., Bindoff, N. L., Boyer, T., Cheng, L. J., Church, J. A., Conroy, J. L., Domingues, C. M., Fasullo, J. T., Gilson, J., Goni, G., Good, S. A., Gorman, J. M., Gouretski, V., Ishii, M., Johnson, G. C., Kizu, S., Lyman, J. M., Macdonald, A. M., Minkowycz, W. J., Moffitt, S. E., Palmer, M. D., Piloa, A. R., Reseghetti, F., Schuckmann, K., Trenberth, K. E., Velicogna, I., and Willis, J. K.: A Review of Global Ocean Temperature Observations: Implications for Ocean Heat Content Estimates and Climate Change, Rev. Geophys., 51, 450-483, doi:10.1002/rog.20022, 2013.

Bindoff, N. L. and Hobbs, W. R.: Oceanography: Deep ocean freshening, Nature Climate Change, 3, 864-865, doi:10.1038/nclimate2014, 2013.

Boyer, T. P., Antonov, J. I., Baranova, O. K., Coleman, C., Garcia, H. E., Grodsky, A., Johnson, D. R., Locarnini, R. A., Mishonov, A. V., O’Brien, T. D., Paver, C. R., Reagan, J. R., Seidov, D., Smolyar, I. V., and Zweng, M. M.: World Ocean Database 2013, NOAA Atlas NESDIS 72, edited by: Levitus, S., Technical Editor: Mishonov, A., Silver Spring, MD, 209 pp., doi:10.7289/V5NZ85MT, 2013.

Church, J. A., Clark, P. U., Cazenave, A., Gregory, J. M., Jevrejeva, S., Levermann, A., Merrifield, M. A., Milne, G. A., Nerem, R. S., Nunn, P. D., Payne, A. J., Pfeffer, W. T., Stammer, D., and Unnikrishnan, A. S.: Sea Level Change, in: Climate Change 2013: The Physical Science Basis. Contribution of Working Group I to the Fifth Assessment Report of the Intergovernmental Panel on Climate Change, edited by: Stocker, T. F., Qin, D., Plattner, G.K., Tignor, M., Allen, S. K., Boschung, J., Nauels, A., Xia, Y., Bex, V., and Midgley, P. M., Cambridge University Press, Cambridge, United Kingdom and New York, NY, USA, 1137-1216, 2013a.

Church, J. A., Monselesan, D., Gregory, J. M., and Marzeion, B.: Evaluating the ability of process based models to project sealevel change, Environ. Res. Lett., 8, 014051, doi:10.1088/17489326/8/1/014051, 2013b.

Domingues, C. M., Church, J. A., White, N. J., Gleckler, P. J., Wijffels, S. E., Barker, P. M., and Dunn, J. R.: Improved estimates of upper-ocean warming and multi-decadal sea level rise, Nature, 453, 1090-1093, doi:10.1038/nature07080, 2008.

Durack, P. J., Wijffels, S. E., and Gleckler, P. J.: Long-term Sealevel Change Revisited: The Role of Salinity, Environ. Res. Lett., 9, 114017, doi:10.1088/1748-9326/9/11/114017, 2014a. 
Durack, P. J., Gleckler, P. J., Landerer, F. W., and Taylor, K. E.: Quantifying underestimates of long-term upperocean warming, Nature Climate Change, 4, 999-1005, doi:10.1038/nclimate2389, 2014b.

Forster, P. M., Andrews, T., Good, P., Gregory, J. M., Jackson, L. S., and Zelinka, M.: Evaluating adjusted forcing and model spread for historical and future scenarios in the CMIP5 generation of climate models, J. Geophys. Res.-Atmos., 118, 11391150, doi:10.1002/jgrd.50174, 2013.

Fyfe, J. C., Gillett, N. P., and Thompson, D. W. J.: Comparing variability and trends in observed and modelled globalmean surface temperature, Geophys. Res. Lett., 37, L16802, doi:10.1029/2010GL044255, 2010.

Gill, A. E.: Atmosphere-Ocean Dynamics, Acadamic Press, San Diego, California, USA, 662 pp., 1982.

Greatbatch, R. J.: A note on the representation of steric sea level in models that conserve volume rather than mass, J. Geophys. Res., 99, 12767-12771, 1994

Gregory, J. M., White, N. J., Church, J. A., Bierkens, M. F. P., Box, J. E., van den Broeke, M. R., Cogley, J. G., Fettweis, X., Hanna, E., Huybrechts, P., Konikow, L. F., Leclercq, P. W., Marzeion, B., Oerlemans, J., Tamisiea, M. E., Wada, Y., Wake, L. M., and van de Wal, R. S. W.: Twentieth-century global-mean sea level rise: is the whole greater than the sum of the parts?, J. Climate, 26, 4476-4499, doi:10.1175/JCLI-D-12-00319.1, 2013a.

Gregory, J. M., Bi, D., Collier, M. A., Dix, M. R., Hirst, A. C., Hu, A., Huber, M., Knutti, R., Marsland, S. J., Meinshausen, M., Rashid, H. A., Rotstayn, L. D., Schurer, A., and Church, J. A.: Climate models without volcanic preindustrial volcanic forcing underestimate historical ocean thermal expansion, Geophys. Res. Lett., 40, 1600-1604, doi:10.1002/grl.50339, 2013b.

Griffies, S. M., Yin, J., Durack, P. J., Goddard, P., Bates, S. C., Behrens, E., Bentsen, M., Bi, D., Biastoch, A., Böning, C. W., Bozec, A., Chassignet, E., Danabasoglu, G., Danilov, S., Domingues, C., Drange, H., Farneti, R., Fernandez, E., Greatbatch, R. J., Holland, D. M., Ilicak, M., Large, W., Lorbacher, K., Lu, J., Marsland, S. J., Mishra, A., Nurser, A. J. G., Salas y Miélia, D., Palter, J. B., Samuels, B. L., Schröter, J., Schwarzkopf, F. U., Sidorenko, D., Treguier, A.-M., Tseng, Y., Tsujino, H., Uotila, P., Valcke, S., Voldoire, A., Wang, Q., Winton, M., and Zhang, X.: An assessment of global and regional sea level for years 1993-2007 in a suite of interannual CORE-II simulations, Ocean Modell., 78, 35-89, doi:10.1016/j.ocemod.2014.03.004, 2014.

Hallberg, R., Adcroft, A., Dunne, J. P., Krasting, J. P., and Stouffer, R. J.: Sensitivity of Twenty-First-Century Global-Mean Steric Sea Level Rise to Ocean Model Formulation, J. Climate, 26, 2947-2956, doi:10.1175/JCLI-D-12-00506.1, 2013.

Ishii, M. and Kimoto, M.: Reevaluation of Historical Ocean Heat Content Variations With An XBT depth bias Correction, J. Oceanogr., 65, 287299, doi:10.1007/s10872-009-0027-7, 2009.

Jackett, D. R., McDougall, T. J., Feistel, R., Wright, D. G., and Griffies, S. M.: Algorithms for density, potential temperature, conservative temperature, and the freezing temperature of seawater, J. Atmos. Ocean. Technol., 23, 1709-1728, doi:10.1175/JTECH1946.1, 2006.

Joughin, I., Smith, B. E., and Medley, B.: Marine Ice Sheet Collapse Potentially Under Way from the Thwaites Glacier Basin, Science, 344, 735-738, doi:10.1126/science.1249055, 2014.
Kouketsu, S., Doi, T., Kawano, T., Masuda, S., Sugiura, N., Sasaki, Y., Toyoda, T., Igarashi, H., Kawai, Y., Katsumata, K., Uchida, H., Fukasawa, M., and Awaji, T.: Deep ocean heat content changes estimated from observations and reanalysis product and their influence on sea level change, J. Geophys. Res., 116, C03012, dio:10.1029/2010JC006464, 2011.

Kuhlbrodt, T. and Gregory, J. M.: Ocean heat uptake and its consequences for the magnitude of sea level rise and climate change, Geophys. Res. Lett., 39, L18608, doi:10.1029/2012GL052952, 2012.

Levitus, S., Antonov, J. I., Boyer, T. P., Baranova, O. K., Garcia, H. E., Locarnini, R. A., Mishonov, A. V., Reagan, J. R., Seidov, D., Yarosh, E. S., and Zweng, M. M.: World ocean heat content and thermosteric sea level change (0-2000 m), 1955-2010, Geophys. Res. Lett., 39, L10603, doi:10.1029/2012GL051106, 2012.

Llovel, W., Willis, J. K., Landerer, F W., and Fukumori, I.: Deepocean contribution to sea level and energy budget not detectable over the pa st decade, Nature Climate Change, 4, 1031-1035, doi:10.1038/nclimate2387, 2014.

Lorbacher, K., Marsland, S. J., Church, J. A., Griffies, S. M., and Stammer, D.: Rapid barotropic sea level rise from ice sheet melting, J. Geophys. Res., 117, C06003, doi:10.1029/2011JC007733, 2012.

Lowe, J. A. and Gregory, J. M.: Understanding projections of sea level rise in a Hadley Centre coupled climate model, J. Geophys. Res., 111, C11014, doi:10.1029/2005JC003421, 2006.

Meinshausen, M., Raper, S. C. B., and Wigley, T. M. L.: Emulating coupled atmosphere-ocean and carbon cycle models with a simpler model, MAGICC6 - Part 1: Model description and calibration, Atmos. Chem. Phys., 11, 1417-1456, doi:10.5194/acp11-1417-2011, 2011.

Mengel, M. and Levermann, A.: Ice plug prevents irreversible discharge from East Antarctica, Nature Climate Change, 4, 451455, doi:10.1038/nclimate2226, 2014.

Moss, R. H., Edmonds, J. A., Hibbard, K. A., Manning, M. R., Rose, S. K., van Vuuren, D. P., Carter, T. R., Emori, S., Kainuma, M., Kram, T., Meehl, G. A., Mitchell, J. F., Nakicenovic, N., Riahi, K., Smith, S. J., Stouffer, R. J., Thomson, A. W., Weyant, J. P., and Wilbanks, T. J.: The next generation of scenarios for climate change research and assessment, Nature, 463, 747-756, doi:10.1038/nature08823, 2010.

Palmer, M. D., Good, S. A., Haines, K., Rayner, N. A., and Stott, P. A.: A new perspective on warming of the global oceans, Geophys. Res. Lett., 36, L20709, doi:10.1029/2009GL039491, 2009.

Palmer, M. D., McNeall, D. J., and Dunstone, N. J.: Importance of the deep ocean for estimating decadal changes in Earth's radiation balance, Geophys. Res. Lett., 38, L13707, doi:10.1029/2011GL047835, 2011.

Palter, J. B., Griffies, S. M., Samuels, B. L., Galbraith, E. D., Gnanadesikan, A., and Klocker, A.: The Deep Ocean Bouyancy Budget and Its Temporal Variability, J. Climate, 27, 551-573, doi:10.1175/JCLI-D-13-00016.1, 2014.

Piecuch, C. G. and Ponte, R. M.: Mechanisms of GlobalMean Steric Sea Level Change, J. Climate, 27, 824-834, doi:10.1175/JCLI-D-13-00373.1, 2014.

Purkey, S. and Johnson, G. C.: Warming of Global Abyssal and Deep Southern Ocean Waters between the 1990s and 2000s: Contributions to Global Heat and Sea Level Rise Budgets, J. Climate, 23, 6336-6351, doi:101175/2010JCL3682.1, 2010. 
Raper, S. C. B., Wigley, T. M. L., and Warrick, R. A.: Global Sealevel Rise: Past and Future, in: Sea-Level Rise and Coastal Subsidence: Causes, Consequences and Strategies, edited by: Milliman, J. and Haq, B., Kluwer, Dordrecht, the Netherlands, 11-45, 1996.

Rhein, M., Rintoul, S. R., Aoki, S., Campos, E., Chambers, D., Feely, R. A., Gulev, S., Johnson, G. C., Josey, S. A., Kostianoy, A., Mauritzen, C., Roemmich, D., Talley, L. D., and Wang, F.: Observations: Ocean, in: Climate Change 2013: The Physical Science Basis. Contribution of Working Group I to the Fifth Assessment Report of the Intergovernmental Panel on Climate Change, edited by: Stocker, T. F., Qin, D., Plattner, G.-K., Tignor, M., Allen, S. K., Boschung, J., Nauels, A., Xia, Y., Bex, V., and Midgley, P. M., Cambridge University Press, Cambridge, United Kingdom and New York, NY, USA, 2013.

Rignot, E., Mouginot, J., Morligem, M., Serossi, H., and Scheuchl, B.: Widespread, rapid grounding line retreat of Pine Island, Thwaites, Smith and Kohler glaciers, West Antarctica from 1992 to 2011, Geophys. Res. Lett., 41, 3502-3509, doi:10.1002/2014GL060140, 2014.

Roemmich, D. and Gilson, J.: The 2004-2008 mean and annual cycle of temperature, salinity, and steric height in the global ocean from the Argo Program, Prog. Oceanogr., 82, 81-100, doi:10.1029/2011GL047992, 2009.

Rose, B. E. J., Armour, K. C., Battisti, D. S., Feldl, N., and Knoll, D. D. B.: The dependence of transient climate sensitivity and radiative feedbacks on the spatial pattern of ocean heat uptake, Geophys. Res. Lett., 41, 1071-1078, doi:10.1002/2013GL058955, 2014.
Russell, G. L., Gornitz, V., and Miller, J. R.: Regional sea level changes projected byb the NASA/GISS Atmosphere Ocean Model, Clim. Dynam., 16, 789-797, 2000.

Rye, C. D., Naveira Garabato, A. C., Holland, P. R., Meredith, M. P., Nurser, A. J., Hughes, C. W., Coward, A. C., and Webb, D.: Rapid sea-level rise along the Antarctic margins in response to increased glacial discharge, Nat. Geosci., 7, 732-735, doi:10.1038/ngeo2230, 2014.

Sen Gupta, A., Jourdain, N. C., Brown, J. N., and Monselesan, D.: Climate Drift in the CMIP5 Models, J. Climate, 26, 8597-8615, doi:10.1175/JCLI-D-12-00521.s1, 2013.

Taylor, K. E., Stouffer, R. J., and Meehl, G. A.: An Overview of CMIP5 and the scenario design, B. Am. Meteorol. Soc., 93, 485498, doi:10.1175/BAMS-D-11-00094.1, 2012.

Trenberth, K. E. and Fasullo, J. T.: Tracking Earth's Energy, Science, 238, 316-317, doi:10.1126/science.1187272, 2010.

Wang, C., Zhang, L., Lee, S.-K., Wu, L., and Mechoso, C. R.: A global perspective on CMIP5 climate model biases, Nature Climate Change, 4, 201-205, doi:10.1038/nclimate2118, 2014.

Wigley, T. M. L., Clarke, L. E., Edmonds, J. A., Jacoby, H. D., Paltsev, S., Pitcher, H., Reilly, J. M., Richels, R., Sarofim, M. C., and Smith, S. J.: Uncertainties in climate stabilization, Climatic Change, 97, 85-121, doi:10.1007/s10584-009-9585-3, 2009.

Yin, J.: Century to multi-century sea level rise projections from CMIP5 models, Geophys. Res. Lett., 39, L17709, doi:10.1029/2012GL052947, 2012. 